\title{
Integrating recovery orientated and realistic evaluation principles into an evaluation of a Partners In Recovery program
}

\begin{abstract}
:
Partners in recovery (PIR) was an Australian government initiative designed to provide support and service linkage for individuals with complex needs living with severe and persistent mental illness. This paper reports the external evaluation process and approach that was undertaken of the Gold Coast Partners in Recovery (GCPIR) initiative between September 2015 and December 2015 regarding the achievement of Partners in Recovery (PIR) outcomes. The evaluation of this consortia-based initiative was framed using principles of realistic evaluation and recovery-oriented practice. Numerous evaluations of similar initiatives have recently been undertaken, each adopting different approaches and methods in accordance with local needs and expectations (Trankle and Reath, 2019; Hancock et al. 2018; Cheverton and Janamian, 2016). The incorporation of realistic evaluation with recovery oriented principles in this mixed methods research design, however, offers a unique perspective. This can be used to inform future developments in evaluative practice particularly in the area of recovery-oriented services and/or partnership-focussed, capacity building initiatives.
\end{abstract}

Keywords: realist evaluation, recovery, mental health, partnership, consortium. 


\section{Introduction}

by improving collaboration, coordination and integration of services and supports from the multiple sectors clients may come into contact with (and could benefit from)

Partners in recovery (PIR) is an Australian government initiative designed to provide support and service linkage for individuals with complex needs living with severe and persistent mental illness. It aims to improve collaboration, coordination and integration of services and supports from the multiple sectors clients may benefit from. Local PIR consortiums have been established across the country. This paper examines and reports the evaluation process and approach undertaken for one local PIR initiative, the Gold Coast Partners in Recovery (GCPIR). The evaluation was an external evaluation undertaken between September and December 2015, regarding the achievement of Partners in Recovery (PIR) outcomes (as identified in the program logic for the national evaluation). The evaluation was framed using realistic evaluation principles (Pawson \& Tilley, 2004; Porter \& O'Halloran, 2012) with recovery-oriented principles and practices embedded in the research design.

The GCPIR consortium Operational Management Group accepted the researchers' proposed tender for a context centred evaluation (Comfort \& Hoggarth, 2010), because it allowed for dynamic changes and diverse viewpoints to be recognised. The evaluation engaged a total of 32 stakeholders including Advisory Group members and internal stakeholders such as Facilitators, Operational Management Group (OMG) and Sponsor Group members. An iterative approach using key principles of realist evaluation was deemed appropriate for considering the local context and what was working for who and in which circumstances. The evaluators also sought to integrate a recovery oriented framework, derived from mental health practice, into the design of the evaluation as this was consistent with the overall objectives of the program. Although there are diverse interpretations of recovery oriented mental health practice (Davidson, Rakfeldt, \& Strauss, 2010), the general focus is on hope, self-determination, self-management, empowerment, and inclusion (Gilburt, Slade, Bird, Oduola, \& Craig, 2013;Commonwealth of Australia, 2013; Le Boutillier et al. 2015). Recovery orientated techniques including strengths-based or an appreciative enquiry approach (Cooperrider, 2005; Mellish, 2000) to interviewing and the use of metaphor were integrated into the evaluation design.

Numerous evaluations of other PIR initiatives have recently been undertaken, each adopting different approaches and methods in accordance with local needs and expectations (see for 
example, Trankle and Reath, 2019; Hancock et al. 2018 and Cheverton and Janamian, 2016). The incorporation of realistic evaluation principles which integrate recovery oriented principles practices in this evaluation, however, offers a unique perspective. Gulliver (2018) did present an account of an evaluation of PIR in Canberra using a realist approach and the concept of recovery, but focused on operationalising the concept of recovery rather than embedding a recovery framework into the research design. Inspired by the Australasian Evaluation Society's (2019) priority to influence and promote evaluation practice, it is hoped that this paper contributes to the diverse application of realist evaluation principles in practice (Kazi, 2007; Weir, 2007) and particularly the integration of recovery oriented practices and realist evaluation principles in evaluative research. Lessons learned from the evaluation have the potential to harness current change dynamics and diverse views towards future change processes of continued hope, respect, self-determination and inclusivity.

\section{Background to the evaluation}

The evaluation was conducted by Griffith University researchers and was funded by the local Primary Health Network following the conclusion of a tendering process. The aim of this external program evaluation was to determine whether the Gold Coast Partners in Recovery (GCPIR) initiative has been successful, to date, in improving system responses to and outcomes for people with severe and persistent mental illness who have complex needs. The overarching strategic objective of PIR was to facilitate improved coordination of clinical and other supports and services to deliver wrap around care, which is individually tailored to a person's needs. Another strategic objective was to strengthen partnerships and facilitate interagency collaboration in order to establish more streamlined and coordinated referral pathways as well as promote a community based recovery model to underpin all clinical and community support services (Department of Health and Aging, 2012a).

Consistent with the national program, the aims of GCPIR were to improve the system response to and outcomes for, people with severe and persistent mental illness who have complex needs by:

1. Facilitating better coordination of clinical, other supports and services to deliver "wrap around" care individually tailored to need. 
2. Strengthening nurturing and growing partnerships, securing better links between clinical and community support organisations delivering services to the PIR Group.

3. Improving and building on referral pathways, facilitating improved access to the range of services and supports needed.

4. Promoting a community based recovery framework to underpin all clinical and community support service (Department of Health and Aging, 2012b, p. 5; Gold Coast Medical Local, 2012).

The background to the recovery movement emerged in the 1980s when consumers began publishing their experiences of recovery from severe mental illness (Andresen, Oades \& Caputi, 2003). Since the first National Mental Health Strategy in 1992, relapse prevention and related concepts of recovery have been a major focus of the mental health policy agenda (Rickwood, 2006). Consumers first understood the process of recovery in terms of finding hope, re-establishing their identities, finding meaning in life and taking responsibilities for their recovery (Andresen et al., 2003). Consequently, clinicians began reorienting their practice to support recovery-based processes. Andresen and colleagues (2003) developed and validated a five-stage model for the achievement of recovery-oriented outcomes. The five stages comprised moratorium; awareness; preparation; rebuilding and a growth or resilience/wellbeing phase (Andresen et al., 2003).

In mental health, recovery does not always refer to the process of becoming symptom-free from serious mental illness (SMI). For many people, the concept of recovery is about staying in control of their life whether or not they are experiencing on-going or recurring symptoms. This thinking emphasises self-determination and opportunities to experience everyday life pursuits such as education, employment, sexuality, friendship, spirituality and community membership beyond the limits of the disorder and the mental health system. These experiences are consistent with the person's own goals, values and preferences (Davidson \& Roe, 2007), and primarily influenced how recovery-oriented principles were understood and applied in the current context.

The concept of recovery is nevertheless somewhat complex (Davidson, Rakfeldt, \& Strauss, 2010). Despite the concept's growing prominence in mental health policy, there remain differences in perspective and a lack of specific guidance for service provision (Gilburt, Slade, Bird, Oduola, \& Craig, 2013). Whilst there is no one single agreed definition of 
recovery in the literature, the term has increasing currency in mental health service systems internationally and is employed in a variety of ways. Consequently, there is some ambiguity around its definition and translation into practice (Commonwealth of Australia, 2013). Le Boutillier and colleagues (2015) found that mental health professionals conceptualise recovery in three different ways: clinical recovery, as defined by mental health professionals; personal recovery, as defined by consumers; and service-defined recovery, which extends the application of recovery into the goals and arrangements of an organisation. However, central to all recovery paradigms are hope, self-determination, self-management, empowerment and advocacy, and these tenets were therefore embedded in the evaluation design.

As part of the program logic identified in the National Evaluation Framework (Australian Government, 2013), and shared by the GCPIR, a hierarchy of outcomes were specified, which each PIR was expected to be working towards (refer to Table 1). As national program evaluation was also undertaken (see for example, URBIS, 2014), the scope of the current evaluation was limited to the GCPIR and its arrangements and achievements to date.

Table 1. PIR Outcomes Hierarchy

\begin{tabular}{|c|c|}
\hline & $\begin{array}{l}\text { Outcomes identified in the Program Logic of PIR Evaluation } \\
\text { Framework }\end{array}$ \\
\hline \multirow{9}{*}{$\begin{array}{l}\text { Immediate } \\
\text { outcomes }\end{array}$} & The network of PIR Organisations is established \\
\hline & $\begin{array}{l}\text { PIR Organisation staff are recruited and appropriate training and capacity building } \\
\text { has been provided to staff as requested }\end{array}$ \\
\hline & Care coordination and support model is agreed and in place \\
\hline & Referral, intake and assessment processes are developed and in place \\
\hline & $\begin{array}{l}\text { The Reporting Framework is developed and implemented effectively by the } \\
\text { Department of Health and PIR Organisations }\end{array}$ \\
\hline & $\begin{array}{l}\text { Appropriate data systems are implemented to enable accurate and timely reporting, } \\
\text { information sharing, and client information management }\end{array}$ \\
\hline & $\begin{array}{l}\text { Clear governance and management structures are in place at Programme and } \\
\text { Regional level }\end{array}$ \\
\hline & $\begin{array}{l}\text { Lead agency and partner organisations operate effectively as a consortium in the } \\
\text { establishment and early implementation phases }\end{array}$ \\
\hline & $\begin{array}{l}\text { PIR Organisations are accepting clients in the Programme in line with agreed } \\
\text { inclusion criteria }\end{array}$ \\
\hline \multirow{4}{*}{$\begin{array}{l}\text { Intermediate } \\
\text { outcomes }\end{array}$} & Level of client intake is in line with expectations and funding \\
\hline & $\begin{array}{l}\text { Level of coordination between clinical and community support service providers is } \\
\text { improved }\end{array}$ \\
\hline & $\begin{array}{l}\text { Service providers have engaged in new and more efficient partnerships to meet the } \\
\text { needs of people with severe and persistent mental illness with complex needs }\end{array}$ \\
\hline & $\begin{array}{l}\text { Clinical and community support services are operating according to a community- } \\
\text { based recovery model }\end{array}$ \\
\hline
\end{tabular}




\begin{tabular}{|l|l|}
\hline \multirow{4}{*}{$\begin{array}{l}\text { Ultimate } \\
\text { outcomes }\end{array}$} & $\begin{array}{l}\text { PIR clients and their families/carers have improved access to required and } \\
\text { culturally appropriate services and supports }\end{array}$ \\
\cline { 2 - 3 } & PIR Organisations are operating in an effective and cost-efficient manner \\
\hline \multirow{4}{*}{\begin{tabular}{l} 
Clients participating in PIR have improved clinical functioning \\
\cline { 2 - 2 }
\end{tabular}} & $\begin{array}{l}\text { Clients participating in PIR have improved access to stabled housing increased } \\
\text { participation in employment, education and social activities }\end{array}$ \\
\cline { 2 - 2 } & Clients participating in PIR have improved quality of life \\
\cline { 2 - 2 } & Clients and carers are satisfied with the support they have received through PIR \\
\cline { 2 - 2 } & Families and carers of people participating in PIR have an improved quality of life \\
\cline { 2 - 2 } & $\begin{array}{l}\text { PIR is an effective coordination model for supporting people with severe and } \\
\text { persistent mental illness with complex needs }\end{array}$ \\
\hline
\end{tabular}

The aim of this externally conducted program evaluation was to determine whether the Gold Coast Partners in Recovery (GCPIR) initiative has been successful, to date, in improving system responses to and outcomes for people with severe and persistent mental illness who have complex needs. The overarching strategic objective of the PIR initiative is to facilitate improved coordination of clinical and other supports and services to deliver wrap around care, which is individually tailored to a person's needs. Another strategic objective is to strengthen partnerships and facilitate inter-agency collaboration in order to establish more streamlined and coordinated referral pathways as well as promote a community based recovery model to underpin all clinical and community support services (Department of Health and Aging, 2012).

\section{Methods}

The collection of evaluation data was undertaken between September and December, 2015. An expedited ethical review was undertaken for the evaluation of the GCPIR and approval was obtained prior to commencing the project (Griffith University project reference HMR/06/HREC).

Participants were selected using a purposive sampling method with the details of key stakeholders directly involved in the delivery and governance of the GCPIR programs. These included stakeholders both internal and external to the program as represented by the Advisory Group and PIR Facilitators, Coordinators (and Program Management) and the Sponsor Group. A total of 32 people participated in interview processes for the evaluation (n $=32$ ). 
The researchers' tender to the GCPIR consortium members proposed a context centred evaluation which allowed for dynamic changes and diverse viewpoints. This approach was primarily based on key principles of realist evaluation (see Pawson \& Tilley, 2004; Porter \& O’Halloran, 2011; Astbury, 2013 for a detailed review). A realist or realistic evaluation approach considers how the program's mechanism (reasoning and resources) interact with the context in which the program operates (for example, organisational, historic, geographical). According to Pawson and Tilley (2004) it is only through gaining an understanding of the interaction between a program's contexts and mechanisms that we can properly comprehend how a program's outcomes are achieved. The utility of realistic evaluation placing context at the centre is valuable in informing programs that are "effective and responsive, and employing contextually appropriate mechanisms that enhance communities' benefits" (Mukova-Moses, 2017; see also Punton, Vogel \& Lloyd 2016). Accordingly, the evaluation was undertaken in three stages, as summarised in Table 2. These stages sought to draw "on prior knowledge, actively entertaining alternative accounts, and attempting to make a case form one as best" (Weir, 2007, p.50).

Table 2. Summary of Realist Evaluation Phases

\section{Phase}

(1) Identification of program theory and preliminary hypotheses re: ContextMechanism-Outcome (CMO) configurations

(2) Testing the program theory

(3) Refining the program theory

\section{Source of data and activities undertaken}

- Desktop review of PIR guidelines, PIR Evaluation Framework and material provided by GCPHN (including client satisfaction results)

- Review of literature on recovery-based practice

- Group interview/workshop with PIR facilitators

- Key informant interviews with Advisory Group, Operational Management Group and Sponsor group members

- Analyses and interpretation of interview data

- Presentation of preliminary report and workshopping of results

- Refinement of CMO configurations 
The first stage comprised a review of the existing literature and documentation both locally and nationally relating to the Partners in Recovery program. This enabled the evaluators to identify the principles, aims and objectives underlying the program, which allowed the evaluation to be placed in a local context and helped shape initial hypotheses and lines of enquiry; upon which a semi-structured interview schedule was developed to be used with the PIR facilitators and other key informants. A consumer voice or satisfaction survey had recently been completed and the results were used by the evaluation team to incorporate consumer perspectives.

The second phase was comprised of primary data collection and analysis. The data collection process was iterative so that information from the Facilitators workshop could be used to further guide planning for the key informant interviews and concordantly, the workshop. Key informant interviews are generally considered to be a useful tool for gathering data within a limited timeframe (Legard, Keegan \& Ward, 2003; Miller \& Crabtree, 2004). The interview technique preserves the multivocality and complexity of the different experiences of different participants (Miller \& Crabtree, 2004). Viewpoints were elicited and clarified as informants expressed their understanding of the project and their experiences to date, which meant that both the content, context and any implications could be clarified immediately (Lawson, 1985). Interview participants also completed a stakeholder survey (77 percent return rate) to gauge areas that needed further focus over the next twelve months. This was based on the program logic and the degree to which participants felt that the immediate, intermediate and ultimate outcomes had been fully achieved, partially achieved or were yet to be progressed.

Consistent with the program's objective and service context, one way in which the evaluators integrated recovery oriented concepts into the research design was to use appreciative inquiry (or strengths based) interviewing techniques (e.g. Mellish, 2000). This was done to value partners' contributions and build on areas of strengths of the GCPIR program while also identifying future opportunities for improvement. All interview data was manually recorded.

The data were analysed thematically (e.g. Doi, Jepson \& Cheyne, 2015). An inductive approach was used where themes emerged from the data according to different types, structures and ideas (Doi et al., 2015; Lofland \& Lofland, 1995). The typology of this 
information helped identify unique perspectives and common threads that became evident when particular issues were mentioned more frequently (Mason, 2002). Identification of responses from different internal and external key informants, at the level of advisory group members, facilitators, the Operational Management Group and Sponsor Group were used to provide further context for consideration of the results.

As a result of the data collection process, a number of common and unique threads were identified from the range of stakeholder views that were gathered. Recommendations, based on this analysis, were coined using the program's overall aims and objectives. A preliminary report was disseminated to all research participants on 20 November 2015 to consider prior to a workshop held on 27 November, 2015. This report was finalised based on the feedback received and further discussions at the workshop. During the workshop process a metaphor was used to recognise everyone's unique perspectives and also validate the different views and experiences. The metaphor was introduced by the evaluation team to help make sense of and refine evaluation findings with the program's stakeholders in the workshop.

\section{Results}

Material provided by GCPIR (Phase 1) included reporting to the Department of health and Aging and a recent consumer voice or satisfaction survey (GCPIR, 2015; GCPIR, 2014a; 2014b; Mental Health Association of Queensland, 2015), as well as the literature on recovery based approaches. A rapid appraisal of this material indicated significant success with participants reported the PIR program had significantly enhanced their experience of recovery leading to an improved quality of life, but also opportunities for improvement in filling service gaps. Also, the complexities of working within a consortia model had presented some difficulties. Some of the identified issues included aspects of leadership, communication, process consistency, relationships, and reaching agreements amongst all six members of the consortia. The feedback from facilitators and coordinators of the program suggested there is a lack the capacity to undertake the system reform work that was intended and that the time frame to achieve sustained systems change within the initial three years has proved challenging (GCPIR, 2015; GCPIR, 2014a). These issues provided the basis for interview questions in the primary data collection stage (Phase 2). 
Although most stakeholders submitted their survey responses either prior to or at the interview, some participants said they would complete this following the interview. The resulting response rate was $77 \%$. The results of this proved useful in highlighting areas of achievement, to date, and where future action was still required. Indeed, the vast majority believed the immediate outcomes were achieved. There was also general agreement that it had achieved, or was partially achieving, both intermediate outcomes and ultimate outcomes, as identified in the Outcomes Hierarchy (Australian Government, 2013). Some specific areas or actions which needed to be addressed moving forward were also able to be identified. specified for the

More detailed results relating to the program itself and achievement of program objectives are not reported in this paper as they were for the use of consortium partners only. Nevertheless, the results of this evaluation, in particular the key informant interview data indicated, at a process level, a need to redress some internal dynamics; primarily in relation to continuing to invest maintaining norms of trust and reciprocity within the consortia.

Recommendations, based on the analysis of evaluation data, were coined using the program's overall aims and objectives. A preliminary report was disseminated to all research participants in early November 2015 to consider prior to a workshop held at the end of that month. The report was then finalised based on the feedback received and further deliberations at the workshop.

During the workshop process (Phase 3) a metaphor was introduced by the evaluation team to help make sense of and refine evaluation findings - particularly in relation to views expressed that on face appeared to be contradictory or diametrically opposed to other views elicited. Specifically, the metaphor of an elephant with its trunk raised was selected to help make sense of the complex, and at times, seemingly opposing views reported by different stakeholders. The allegory was akin to the Chinese metaphor regarding blind people feeling an elephant, used as a metatheory of organisations (Tsui, 1998). According to this metaphor, organisations are just like an elephant, with staff representing a group of blind people exploring and feeling the elephant, which from any one person's perspective is too big to grasp. As Tsui (1998) has explained, each blind person can only hold one part of the 
elephant, and nobody can tell the whole or true picture. Although everyone thinks they have the whole truth, in reality, it is much bigger and more complex than any one view of the elephant. The metaphor was used to recognise everyone's unique perspectives but also to validate different views and experiences (Tsui, 1998).

Despite the demonstrated merits of the different methods used in the current evaluation, a number of limitations can also be noted, many of which included timeframe challenges and some logistical issues. As this was an externally conducted evaluation, it needs to be noted that for pragmatic reasons (e.g., ethics approval and time constraints) this evaluation relied on some secondary sources such as the consumer satisfaction survey results that had been undertaken and other documents that were provided. While the evaluation team sought to ensure two researchers would be present to conduct all interview processes, due to time constraints and some unforeseen circumstances, a total of seven participants (two sponsor groups, four advisory groups, and one operational management group member) were interviewed by a single researcher. Three of these interviews needed to be conducted over the phone.

As the researchers felt it was important to ensure research methods were consistent, the same interview schedule was used for key informant interviews. However, the resulting differences evident in the views of stakeholder groups suggest that, in hindsight, it may have been preferable to ask different questions of different groups. Nevertheless, the interview process was semi-structured and allowed for each conversation to differ and for the use of prompt questions to further explore and clarify any issues raised. The evaluation team did have some difficulties in making sense of the heterogeneous views expressed in the interviews before the introduction of the elephant metaphor. As different members of the research team conducted the interviews, some triangulation was required for thematic analysis purposes, drawing on the different perspectives of evaluation team members as well as the range of documents that had been provided.

\section{Discussion}

In general, and despite concern and hesitation about "another evaluation process," positive feedback was received throughout each stage of the evaluation from the project managers and 
and this was re-affirmed in the final workshop. This included follow-up within the first two months and 12 months of completing the evaluation, with reports suggesting that significant work had been progressed in response to the recommendations and that the service had received continued funding and was working to achieving all program objectives. Although some limitations of the approach have been noted, the evaluation approach was overall deemed to be successful in that it served to facilitate the continuous improvements required and the celebration of the major achievements; considered key to building on the momentum established. Further evidence included that the available indicators of stakeholder satisfaction were good, and on a process level, the approach embodied many of the principles of recovery-oriented practice which was appropriate to the service context.

Framing the evaluation using realist evaluation principles (Pawson \& Tilley, 2004; Porter \& O'Halloran, 2011) in the design of the evaluation assisted in exploring and unpacking some of the complexities involved in the evaluation of such a consortia-based initiative. A realist evaluation approach considers how the program's different activities or mechanisms lead to different outcomes in different contexts (for example, across different organisations, geographical locations, or age groups). According to Pawson and Tilley (2004) it is only through gaining an understanding of the interaction between a program's contexts and mechanisms that we can properly comprehend how or when its outcomes are achieved. The use of an iterative evaluation approach whereby the data was analysed and reported at different phases to check understandings and gain further insights enabled the evaluators to incorporate stakeholder feedback, but more importantly, increase ownership of the results and suggested recommendations (Legard et al., 2003; Miller \& Crabtree, 2004). This included the circulation of a preliminary evaluation report and further workshopping of the results.

As noted the realist evaluation principles used in the current evaluation sought to embody recovery-oriented practices in identifying areas of achievement and relative strength and those areas where further effort is still required to support the recovery of people with severe and persistent mental health needs. Applying recovery oriented practice to the area of organisational partnerships provided some challenges, however. Organisational partnerships are increasingly seeking to determine their effectiveness and evaluate their efforts and collective impacts. Nevertheless, approaches to evaluating the collective impact of community-based initiatives are continually emerging (Flood, Minkler, Hennessey Lavery, Estrada, \& Falbe, 2015; Asthana et al., 2002; Dowling, Powell \& Glendinning, 2004). All 
partnerships have their dynamics, but the focus on a partnership established to promote recovery-oriented practices and improve outcomes for people with severe mental illness presented specific challenges in this evaluation. This required a degree of flexibility in meeting the diverse needs of stakeholders. Just as recovery from a consumer perspective can be understood to be a five-stage process (e.g., Andresen et al., 2003), for a consortium that was already "aware" of what is possible (and had been achieved locally previously), the evaluation could be seen to represent the "preparation" and "rebuilding" phases of the process of recovery. That is, taking stock of relative strengths and weaknesses and identifying ways forward, which is a prerequisite for Andresen et al.'s (2003) final stage of the recovery process: "growth' or self-fulfilment.

Partnership approaches have become a commonplace theme in public health, human services, and international development (Asthana et al., 2002; Gomez-Bonnet \& Thomas, 2015). In Australia, partnerships refer to agreements made to work towards shared goals, in recognition that more is achieved together than working separately (Council on Federal Financial Relations, 2011). The first challenge in evaluating partnerships can be agreeing on the (shared) terms, which include "communicating," "cooperating," "networking," and “collaborating," all of which may be interchangeable (Frey et al., 2006; Riggs et al., 2014). An agreement on the definition of terms is needed so that there is a shared understanding of different ways in which partnerships operate (Dickinson, 2006). A second challenge is to identify at which level partnerships occur, both within and between organisations and in the interactions between people in each organisation. Indeed, these interactions are central aspects of how partnerships work (Bailey \& Koney, 2000: Gadja, 2004). Partnerships that comprise several layers of management with more than two large organisations are more complicated to evaluate and manage than smaller numbered organisations (Gomez-Bonnet \& Thomas, 2015), hence evaluators generally adopt data collection methods which can provide meaningful information about important aspects of partnership processes and outcomes (Halliday, Asthana \& Richardson, 2004; Mandel \& Keast, 2004). Power imbalances among members, different understandings of shared goals and unique perspectives can present further challenges (Rodgers et al., 2014). In the current evaluation context, the evaluators were conscious of the need to both embody recovery-oriented practices in evaluating the function and effectiveness of this specific consortium and to apply an iterative process of making sense of and refining evaluation findings and to foster buy-in or ownership of these results as a result of this process. 
Within the Australian context, a number of tools have been developed to measure mental health recovery focusing on individual recovery and recovery orientation of services over and above the need to comply with Australia's National Standards for Mental Health Services (2010). For example, the Australian Mental Health Outcomes and Classification Network Review of Recovery Measures identified four measures that may be particularly relevant: the Recovery Oriented Systems Indicators Measure (ROSI), Recovery Self-Assessment (RSA), Recovery Oriented Practice Index (ROPI) and Recovery Promotion Fidelity Scale (RPFS) (Burgess, Pirkis, Coombs, \& Rosen, 2010). Slade (2009) has also noted the application of the Practice Guidelines for Recovery-Oriented Behavioral Health Care (Connecticut Department of Mental Health and Addiction Services, 2006), the Fidelity Assessment Common Ingredients Tool (FACIT) for peer-run measures, the Pillars of Recovery Service Audit Tools (PoRSAT) for informing service development, and the Recovery-promoting Relationships Scale, a consumer-rated measure of the extent to which relationship supports the recovery process. While the potential utility and application of such measures were noted, the context of evaluating a consortium presented additional complexities including aspects of leadership, communication, process consistency, relationships, and reaching agreements. Nevertheless, the National Framework for Recovery-Oriented Mental Health Services (Australian Health Ministers' Advisory Council, 2013) provides specific milestones for these partnerships to achieve, and this was used instead of generic measures of partnership effectiveness; for instance, the Nuttfield Partnership Assessment Tool (Halliday et al., 2004) and Partnership Analysis Tool (VicHealth, 2011).

The resulting mixed method approach used was therefore designed specifically for the required timeframes and for the purpose of this evaluation, which required a determination of the degree to which outcomes were being achieved, and contextual considerations to make sense of the how and why. The utilisation of mixed method designs are increasingly recognised in both health and organisational settings (Greenhalgh, Robert, MacFarlane, Bate \& Kyriakidou, 2004; Palinkas et al., 2011; Soh \& Martinov-Bennie, 2011), as well as realist evaluation (Kazi, 2007; Weir 2007; Mukova-Moses, M. (2017). Although the mixed methods approach can be labour intensive and involve multiple stages of data collection, the combination of approaches also overcomes the deficiencies of any one method and the additional sources of information provided help counter any pre-conceived notions (Babbie, 2013). Indeed, Weir (2007, p. 50-51) argues that a combination of qualitative and quantitative 
methods are needed in realist evaluation to fully understand causal mechanisms. The resulting combination provided a more detailed and richer understanding of the issues (Creswell \& Plano Clark, 2007), which was necessary given the number and diversity of stakeholders involved in the consortium.

To value previous and existing efforts and experiences (and embody the principles of hope and optimism of a recovery orientated framework), appreciative inquiry and the use of metaphor emerged as one of the key research methods used in the evaluation. Appreciative inquiry is commonly used to focus on the positives and to emphasise strength building (Cooperrider \& Whitney, 2005). However, what one stakeholder sees as a strength others may interpret differently. Thus, to make sense of such complexities, storytelling methods, narratives, and metaphors can be used to explain different positions in a way that more actively involves stakeholders (Rhodes \& Brown, 2005). In the current evaluation, the use of the metaphor of an elephant with its trunk raised, was considered appropriate not only to embody a sense of optimism and hope, but also to create a common or shared understanding of the complexities of the consortium, service model, and specific work processes (e.g., Lakoff and Johnson, 1980). The metaphor was seen as novel and used as the basis of a number of ongoing activities and subsequent promotions. Toy stress ball elephants were gifted to participants as part of the workshop (see figure 3). 


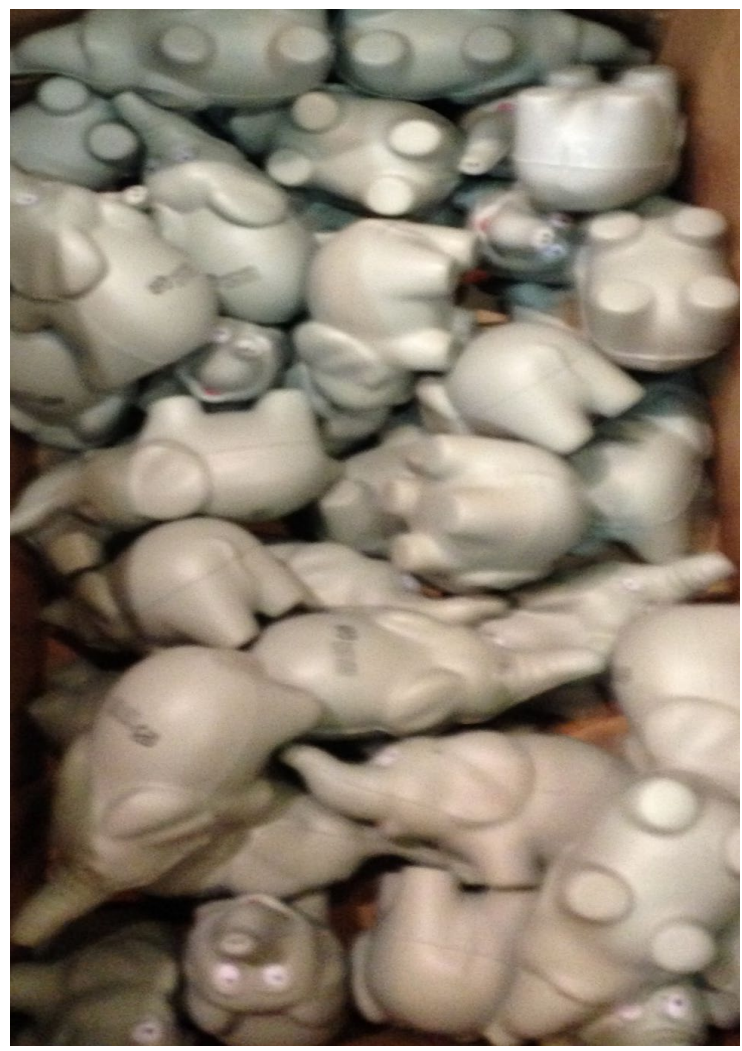

Elephant stress balls were provided to workshop participants as a token of appreciation for their participation in the evaluation process and their commitment to PIR. The elephant (with its elevated trunk) was used to reflect the optimism of recovery-oriented practices and to build on the metaphor used by Evaluators to validate the different perspectives of all stakeholders involved in the GCPIR - i.e. how you would describe what an elephant looks like from the front view is very different from the back view, side view or the views from above or below the elephant yet all are necessary and equally important in order to make sense of the whole.

Further research and sharing of practice is needed to better inform the evaluation of complex community-based programs, in particular, the determination of collective impacts to improve community health and wellbeing (Kania \& Kramer, 2011). The approach used in this evaluation may have been appropriate for this community and service context, but it appears to have also been useful for informing how the consortium approaches the achievement of future objectives, both for individual members and collectively. It was primarily focussed on the program objectives to be achieved and its service focus (i.e., the promotion of recoveryoriented practice) as opposed to using established partnership evaluation tools and approaches. Future researchers may choose to incorporate and document their experiences of using established partnership tools using it as part of a broader, interpretive framework that considers outcomes for people with complex needs, including severe and persistent 
experiences of mental illness. Similarly, the approaches used in the current evaluation represent one way or means of embodying a recovery-oriented evaluation framework for partnerships using realist evaluation principles; however, there are numerous other approaches that evaluators could also take. It is therefore hoped that greater informationsharing will enable us to continue to apply and refine the best methods of evaluating partnership based, recovery-focused service models in the future.

\section{References}

Andresen, R., Oades, L., \& Caputi, P. (2003). The experience of recovery from schizophrenia: Towards an empirically validated stage model. Australian and New Zealand Journal of Psychiatry, 37(5), 586-594. doi:10.1046/j.1440$1614.2003 .01234 \mathrm{x}$

Asthana, S., Richardson, S., \& Halliday, J. (2002). Partnership working in public policy provision: A framework for evaluation. Social Policy and Administration, 36(7), 780 795. doi:10.1111/1467-9515.00317

Australian Health Ministers' Advisory Council. (2013). National framework for recoveryoriented mental health services: Guide for practitioners and providers. Retrieved from

http://www.health.gov.au/internet/main/publishing.nsf/content/67D17065514CF8E8C A257C1D00017A90/\$File/recovgde.pdf

Australasian Evaluation Society. (2019). Strategic priorities: 2019 to 2022. Retrieved 20 January 2020 from: https://www.aes.asn.au/images/aes_strategicPlan2019_22 finalWeb.pdf

Australian Government. (2010). Australia's National Standards for Mental Health Services (2010). Retrieved 23 January from:

https://www1.health.gov.au/internet/main/publishing.nsf/Content/CFA833CB8C1AA 178CA257BF0001E7520/\$File/servst10v2.pdf

Australian Government. (2013). Partners in Recovery (PIR) Coordinated Support and Flexible funding for People with Severe, Persistent Mental Illness and Complex Needs initiative: PIR Evaluation Framework. Canberra: Department of Health.

Astbury, B. (2013). Some reflections on Pawson's Science of evaluation: A realist manifesto. Evaluation, 19(4), 383-401. doi: 10.1177/1356389013505039.

Babbie, E. (2013). The practice of social research. Belmont, CA: Wadworth Cengage Learning. 
Bailey, D., \& Koney, K. (2000). Strategic alliances among health and human services organizations: From affiliations to consolidations. Thousand Oaks, CA: Sage.

Burgess, P., Pirkis, T., Coombs, T., \& Rosen, A. (2010). Australian mental health outcomes and classification network: Review of recovery measures. Retrieved from http:/www.mentalhealth.va.gov/communityproviders/docs/review_recovery_measure $\underline{\text { s.pdf }}$

Cheverton, J., and Janamian, T. (2016) The Partners in Recovery program: mental health commissioning using value co-creation, Medical Journal of Australia; 204 (7): S38. doi: 10.5694/mja16.00124

Comfort, H., \& Hoggarth, L. (2010) Practical Guide to Outcome Evaluation. London: Jessica Kingsley Publishers.

Commonwealth of Australia. (2013). A national framework for recovery-oriented mental health services. Guide for Practitioners and Providers. Retrieved from http://www.health.gov.au/internet/main/publishing.nsf/Content/B2CA4C28D59C74E BCA257C1D0004A79D/\$File/recovpol.pdf.

Connecticut Department of Mental Health and Addiction Services. (2006). Practice guidelines for recovery-oriented behavioral health care. Retrieved from http://www.ct.gov/dmhas/lib/dmhas/publications/practiceguidelines.pdf

Cooperrider, D. L., \& Whitney, D. K. (2005). Appreciative inquiry: A positive revolution in change $\left(1^{\text {st }}\right.$ ed.). San Fransisco, CA:Berrett-Koehler.

Council on Federal Financial Relations. (2011). Intergovernmental agreement on federal financial relations: Standing council on financial relations. Retrieved from http://www.federalfinancialrelations.gov.au/content/intergovernmental_agreements.as px

Creswell, J. W., \& Plano Clark, V. L. (2007). Designing and conducting mixed methods research. Thousand Oaks, CA: Sage.

Davidson, L., \& Roe, D. (2007). Recovery from versus recovery in serious mental illness: One strategy for lessening confusion plaguing recovery. Journal of Mental Health, 16(4), 459-470. doi:10.1080/09638230701482394

Davidson, L., Rakfeldt, J., \& Strauss, J. S. (2010). The roots of the recovery movement in psychiatry: Lessons learned. Hoboken, NJ: Wiley-Blackwell.

Department of Health and Aging (2012a) Partners in Recovery Initiative Information Paper. Canberra: Australian Government. 
Department of Health and Aging (2012b) Partners in Recovery (PIR) Coordinated Support and Flexible Funding for People with Severe, Persistent Mental Illness and complex Needs initiative. Program Guidelines for the engagement of PIR Organisation 201213 to 2015-16. Australian Government. Canberra: Australian Government.

Dickinson, H. (2006). The evaluation of health and social care partnerships: An analysis of approaches and synthesis for the future. Health \& Social Care in the Community, 14(5), 375-383. doi:10.1111/j.1365-2524.2006.00650.x

Doi, L., Jepson, R., \& Cheyne, H. (2015). A realist evaluation of an antenatal programme to change drinking behaviour of pregnant women. Midwifery, 31(10), 965-972. doi:10.1016/j.midw.2015.06.007

Dowling, B., Powell, M., \& Glendinning, C. (2004). Conceptualising successful partnerships. Health and Social Care in the Community, 12(4), 309-317. doi:10.111/j.13652524.2004.00500.x

Flood, J., Minkler, M., Hennessey Lavery, S., Estrada, J., \& Falbe, J. (2015). The collective impact model and its potential for health promotion: Overview and case study of a healthy retail initiative in San Francisco. Health Education \& Behavior, 42(5), 654668. doi:10.1177/1090198115577372

Frey, B. B., Lohmeier, J. H., Lee, S. W., \& Tollefson, N. (2006). Measuring collaboration among grant partners. American Journal of Evaluation, 27(3), 383-392. doi:10.1177/1098214006290356

Gajda, R. (2004). Utilizing collaboration theory to evaluate strategic alliances. American Journal of Evaluation, 25(1), 65-77. doi:10.1177/1098214004020500105

GCPIR. (2015). Reporting to Department of Health and Aging through completion of schedule 38. (Unpublished paper).

GCPIR. (2014b). Gold Coast Mental Health: Mapping Service Needs for Regional Flexible Funding Investment Considerations. Gold Coast: Gold Coast Partners in Recovery.

GCPIR. (2014a). Completion of Department of Health and Aging template for six month report. (Unpublished paper).

Gilburt, H., Slade, M., Bird, V., Oduola, S., \& Craig, T. K. J. (2013). Promoting recoveryoriented practice in mental health services: A quasi-experimental mixed-methods study. BMC Psychiatry, 13(1), 167-167. doi:10.1186/1471-244X-13-167

Gomez-Bonnet, F., \& Thomas, M. (2015). A three-way approach to evaluating partnerships: Partnership survey, integration measure and social network analysis. Evaluation 
Journal of Australasia, 15(1), 28-37. Retrieved from http://vocational-rehab.com/wpcontent/uploads/SuRGE-6_Evaluating-Partnerships.pdf

Greenhalgh, T., Robert, G., MacFarlane, F., Bate, P., \& Kyriakidou, O. (2004). Diffusion of innovations in service organizations: Systematic review and recommendations. The Milbank Quarterly, 82(4), 581-629. doi:10.1111/j.0887-378X.

Gulliver, A., Morse, A. R., Wilson, N., Sargent, G., Banfield, M. (2018). An Evaluation of a tailored care program for complex and persistent mental health problems: Partners In Recovery program. Evaluation and Program Planning, 68, 99-107

Halliday, J., Asthana, S. N. M., \& Richardson, S. (2004). Evaluating partnership: The role of formal assessment tools. Evaluation, 10(3), 285-303. doi:10.1177/1356389004048279

Hancock, N., Scanlan, J.N, Gillespie. J.A., Smith-Merry, J, Yen, I. 2018 "Partners in Recovery program evaluation: changes in unmet needs and recovery". Australian Health Review. Aug; 42(4), 445-452. doi: 10.1071/AH17004.

Kania, J., \& Kramer, M. (2011). Collective Impact. Stanford Social Innovation Review, 9(1), 36. Retrieved from

http://c.ymcdn.com/sites/www.lano.org/resource/dynamic/blogs/20131007_093137_2 5993.pdf

Kazi, M. A. F. (2007). A Reply to Eric Weir's Review of Realistic Evaluation in Practice. Evaluation Journal of Australasia, Vol. 7, No. 1, 51-54.

Lakoff, G., \& Johnson, M. (1980). Metaphors we live by. Chicago, IL: University of Chicago Press.

Lawson, H. (1985). Reflexivity: The post-modern predicament. Problems of modern European thought series. Retrieved from https://www.qualityresearchinternational.com/Harvey\%20papers/Harvey\%201985\%2 0Review\%20of\%20Lawson.pdf

Le Boutillier, C., Chevalier, A., Lawrence, V., Leamy, M., Bird, V. J., Macpherson, R.,...Slade, M. (2015). Staff understanding of recovery-orientated mental health practice: A systematic review and narrative synthesis. Implement Science, 10(1), 87. doi:10.1186/s13012-015-0275-4

Legard, R., Keegan, J., \& Ward, K. (2003). In-depth interviews. In J. Ritchie \& J. Lewis (Eds.), Qualitative research practice: A guide for social science students and researchers (pp. 138-169). London, England: Sage. 
Lofland, J., \& Lofland, L. (1995). Analyzing social settings: A guide to qualitative observation and analysis. Belmont, CA: Wadsworth.

Mason, J. (2002). Qualitative researching. London, England: Sage.

Mellish, L. (2000). Appreciative inquiry. Retrieved from

http://www.mellish.com.au/Resources/lizarticle.htm

Mental Health Association of Queensland. (2015) Participant Feedback Survey GCPIR. (Unpublished).

Miller, W., \& Crabtree, B. (2004). Depth interviewing. In S. Hesse-Biber \& P. Leavy (Eds.), Approaches to qualitative research: A reader on theory and practice (pp. 185-202). Oxford, England: Oxford University Press.

Mukova-Moses, M. (2017). A case for the advancement of utilisation of realist evaluation in international development: An Oxfam focused illustration. Evaluation Journal of Australasia, 17(2), 37-41.

Palinkas, L. A., Aarons, G. A., Horwitz, S., Chamberlain, P., Hurlburt, M., \& Landsverk, J. (2011). Mixed method designs in implementation research. Administration and Policy in Mental Health and Mental Health Services Research, 38(1), 44-53. doi:10.1007/s10488-010-0314-z

Pawson, R., \& Tilley, N. (2004). Realist evaluation. London, England: British Cabinet Office.

Porter, S., \& O'Halloran, P. (2012). The use and limitation of realistic evaluation as a tool for evidence-based practice: A critical realist perspective. Nursing Inquiry, 19(1), 18-28. doi:10.111/j.1440-18800.2011.00551.x

Punton, M., Vogel, I. \& Lloyd, R. (2016). Reflections from a realist evaluation in progress: scaling ladders and stitching theory. Centre for Development Impact. Retrieved 20 January 2020 from: http://www.ids.ac.uk/publication/reflectionsfrom-a-realistevaluation-in-progress-scaling-ladders-andstitching-theory

Rhodes, C., \& Brown, A. D. (2005). Narrative, organizations and research. International Journal of Management Reviews, 7(3), 167-188. doi:10.1111/j.14682370.2005.00112.x

Rickwood, D. (2006). Pathways of recovery: Preventing further episodes of mental illness. Retrieved from https://www.health.gov.au/internet/main/publishing.nsf/content/85A27F4558113287 CA257BF00021207D/\$File/mono.pdf 
Riggs, E., Block, K., Warr, D., \& Gibbs, L. (2014). Working better together: New approaches for understanding the value and challenges of organizational partnerships. Health Promotion International, 29(4), 780-793. doi:10.1093/heapro/dat022

Rodgers, K. C., Akintobi, T., Thompson, W. W., Evans, D., Escoffery, C., \& Kegler, M. C. (2014). A model for strengthening collaborative research capacity: Illustrations from the Atlanta Clinical Translational Science Institute. Health Education \& Behavior, 41(3), 267-274. doi:10.1177/1090198113511815

Slade, M. (2009). Rethink recovery series: 100 ways to support recovery. Retrieved from http://recoverylibrary.unimelb.edu.au/_data/assets/pdf_file/0005/1391270/100_ways _to_support_recovery.pdf

Slade, M., Amering, M., Farkas, M., Hamilton, B., O'Hagan, M., Panther, G., Perkins, R.,...Whitley, R. (2014). Uses and abuses of recovery: Implementing recoveryoriented practices in mental health systems. World Psychiatry, 13(1), 12-20. doi:10.1002/wps.20084

Soh, D. S. B., \& Martinov-Bennie, N. (2011). The internal audit function: Perceptions of internal audit roles, effectiveness and evaluation. Managerial Auditing Journal, 26(7), 605-622. doi:10.1108/02686901111151332

Trankle, S.A., Reath, J. (2019). Partners in Recovery: an early phase evaluation of an Australian mental health initiative using program logic and thematic analysis. $B M C$ Health Serv Res 19, 524 doi:10.1186/s12913-019-4360-2

Tsui, M.S. (1998). Organizations as elephants: A Chinese metaphor or a metatheory? International Journal of Management, 15(2), 151-160.

URBIS. (2014). Partners in Recovery Evaluation and Monitoring Project. Final Annual Report 2013-14. Department of Health. Retrieved from https://www1.health.gov.au/internet/main/publishing.nsf/Content/1FD43EB98AA86C 7BCA25802800127C1E/\$File/annual14.pdf

Weir, E. (2007). Realist Evaluation in Practice: Health and Social Work [Book Review]. Evaluation Journal of Australasia, 7(1), 48-51.

VicHealth. (2011). The partnership analysis tool. Retrieved from https://www.vichealth.vic.gov.au/search/the-partnerships-analysis-tool 